\title{
Timing of Insulin Injections, Adherence, and Glycemic Control in a Multinational Sample of People with Type 2 Diabetes: A Cross-Sectional Analysis
}

Nicolaas C. Schaper · Annie Nikolajsen • Anna Sandberg •

Sarah Buchs · Mette Bøgelund

Received: July 20, 2017 / Published online: October 23, 2017

(C) The Author(s) 2017. This article is an open access publication

\section{ABSTRACT}

Introduction: We investigated the association of bolus insulin dose timing with demographics, adherence, diabetes education program participation, experience with hypoglycemic events, glycemic control, and patient preference among respondents with type 2 diabetes.

Methods: Adults with type 2 diabetes from 12 countries were recruited to a Web-based self-reported patient preference survey. Adherence was measured using an adapted Morisky Medication Adherence Scale questionnaire.

Results: In total 1483 respondents reported using bolus insulin with 58\% $(n=864)$ dosing bolus insulin before meals (pre-meal cohort), $354(24 \%)$ during or after meals (post-meal

Enhanced content To view enhanced content for this article go to http://www.medengine.com/Redeem/ A3CCF0602570E093.

N. C. Schaper

Department of Internal Medicine, CAPHRI School for Public Health and Primary Care and CARIM Institute, Maastricht, The Netherlands

A. Nikolajsen · A. Sandberg $(\varangle) \cdot$ S. Buchs

Novo Nordisk A/S, Copenhagen, Denmark

e-mail: asdz@novonordisk.com

M. Bøgelund

Incentive, Copenhagen, Denmark cohort), and 265 (18\%) before, during, or after meals (mixed cohort). The mixed cohort was excluded, thus 1218 respondents were included in the analysis. Respondent distribution across $\mathrm{HbA}_{1 \mathrm{c}}$ category differed significantly depending on insulin dose timing $(p=0.0006)$; more respondents in the post-meal cohort (40\%) had $\mathrm{HbA}_{1 \mathrm{c}} \geq 9 \%(74.9 \mathrm{mmol} / \mathrm{mol})$ than in the pre-meal cohort (29\%). The post-meal cohort was significantly more likely to report non-adherence than the pre-meal cohort $(\mathrm{OR}=1.50$, $p=0.01)$ and significantly more often reported participating in diabetes education programs $(p<0.05)$. Seventy-eight percent of all respondents reported preferring bolus insulin administrable whenever convenient.

Conclusions: Approximately 24\% of respondents never comply with guidelines for insulin dose timing, with higher risk of non-adherence and increased participation in diabetes care programs. Respondents dosing insulin post-meal are more likely to have poor glycemic control $\left(\mathrm{HbA}_{1 \mathrm{c}} \geq 9 \%, 74.9 \mathrm{mmol} / \mathrm{mol}\right)$. Given that many respondents had high $\mathrm{HbA}_{1 \mathrm{c}}$ and were non-adherent, a treatment which satisfies patient preference for bolus insulin with flexible dose timing could be considered.

Funding: Novo Nordisk.

Keywords: Type 2 diabetes; Patient preferences; Treatment with insulin; Treatment adherence/compliance 


\section{INTRODUCTION}

Inadequate glycemic control in people with type 2 diabetes is prevalent, with an average of $61 \%$ of people failing to achieve their target $\mathrm{HbA}_{1 \mathrm{c}}$ of $7 \%(53.0 \mathrm{mmol} / \mathrm{mol})$ following the addition of insulin to their oral antidiabetic therapy [1]. $\mathrm{HbA}_{1 \mathrm{c}}$ is closely related to health outcomes in type 2 diabetes with, for example, a $1 \%$ decrease in $\mathrm{HbA}_{1 \mathrm{c}}$ associated with as much as a $21 \%$ reduction in risk of microvascular or macrovascular complications [2].

It has been reported that $18.8 \%$ of people in the USA with type 2 diabetes receive insulin treatment, with over $90 \%$ of these receiving bolus insulin [3]. Clinical guidelines generally recommend that insulin injections are administered within $30 \mathrm{~min}$ before meals $[4,5]$. However, insulin can be dosed post-meal if necessary and rapid-acting formulations are available that can be administered within up to 20 min of starting a meal [6-11].

Time-specific dosing can impact adherence and people may miss, reduce, or mistime insulin doses [12] through eating habits and lifestyle, or recurrent hypoglycemia or fear of hypoglycemia [13-16]. It is well documented that reduced adherence is associated with poorer glycemic control, as measured by $\mathrm{HbA}_{1 \mathrm{c}}$ [17-19], but little research has been published to explore the relationship between appropriate timing of insulin administration and glycemic control.

Education on diabetes and its treatment, particularly diabetes self-management and care, is considered an integral component of type 2 diabetes treatment and improving adherence [20]. These education programs aim to inform people on insulin best practice, the impact of diet and exercise on diabetes, and address patient concerns of side-effects and hypoglycemia [20, 21]. Some studies suggest that health literacy is a determinant of treatment adherence, but the literature is inconsistent as other studies have failed to observe such a relationship [22, 23]. These inconsistencies indicate a need to further investigate the relationship between adherence and education to inform future treatment strategy.
The aim of this study was to examine potential differences with respect to demographics, insulin adherence, diabetes education program participation, experience with hypoglycemic events, glycemic control, and respondent preference across insulin dose timing in patients with type 2 diabetes on insulin therapy.

\section{METHODS}

This was a cross-sectional analysis of a Web-based self-reported survey and was part of an international patient preference study, the methodology of which has previously been described by Feher et al. [24]. The survey was developed in English before translation to the languages of each country and respondent completion time was approximately $15 \mathrm{~min}$.

Respondents were recruited from a Web-based panel (Userneeds, SSI), with members originally recruited through telephone or online advertisements. Recruitment covered 12 countries across North America (Canada and USA), South America (Argentina, Brazil, Chile, Colombia, and Mexico), and Europe (France, Germany, Italy, Netherlands, and UK). In the original study, respondents were included if they had been diagnosed with type 2 diabetes more than 6 months ago and were treated via subcutaneous insulin (excluding pump or continuous subcutaneous insulin infusion) for 3 or 4 months. The current analysis assessed only the subgroup of respondents who reported receiving bolus insulin. Respondent involvement was voluntary with consent provided to participate. Data were collected between August 2014 and February 2015.

The current analysis focused on the elements of the survey that pertained to insulin dose timing, respondent demographics, insulin adherence, participation in diabetes education programs, experience with hypoglycemic events, glycemic control, and respondent preference.

The European Society for Opinion and Marketing Research and European Pharmaceutical Market Research Association regulations were followed to ensure respondent anonymity. All 
procedures followed were in accordance with the ethical standards of the responsible committee on human experimentation (Institutional Review Board Services, Canada) and with the Helsinki Declaration of 1964, as revised in 2013. Informed consent was obtained from all patients for being included in the study.

\section{Insulin Dose Timing}

Data were categorized on the basis of insulin dose timing. Respondents that only administered their insulin prior to eating were categorized as the pre-meal cohort, and respondents that reported administering insulin during or after mealtime were defined as the post-meal cohort. Patients that varied their dosing between before, during, or after eating were excluded from further analyses, as it would not be possible to link outcomes to time of bolus injections in these subjects. Respondents that reported "other" dosing times were also excluded under the assumption that these respondents were treated with basal insulin and reported that they received bolus insulin by mistake.

\section{Insulin Adherence}

Adherence was assessed using an adapted Morisky Medication Adherence Scale (MMAS-8), comprising eight questions examining medicine-taking behavior to determine adherence $[25,26]$. The MMAS- 8 questionnaire was adapted to insulin treatment, with the word "insulin" replacing "treatment" or "medication" in each question. Responses to all items of the MMAS-8 were used to develop scores reflecting non-adherence. The score increased by one with each response indicating non-adherent behavior and higher scores indicated a greater level of non-adherence. Non-adherence was defined as a score of 3 or more out of 8 , based on the cutoff point previously validated by Morisky et al. $[25,26]$.

\section{Glycemic Control and Experience with Hypoglycemic Events}

For the purposes of this analysis, $\mathrm{HbA}_{1 \mathrm{c}} \geq 9.0 \%$ was used to define high $\mathrm{HbA}_{1 \mathrm{c}}$ to cover all demographics as target values vary across different patient populations. $\mathrm{HbA}_{1 \mathrm{c}}$ values greater than $15 \% \quad(140.4 \mathrm{mmol} / \mathrm{mol})$ were deemed unrealistic according to physician guidance. Thus, respondents with missing $\mathrm{HbA}_{1 \mathrm{c}}$ results and those with $\mathrm{HbA}_{1 \mathrm{c}}$ results above 15\% $(140.4 \mathrm{mmol} / \mathrm{mol})$ were excluded from the analysis of respondent $\mathrm{HbA}_{1 \mathrm{c}}$. "Severe" or "major" hypoglycemia was defined as hypoglycemia requiring assistance from another person to aid recovery. Self-managed hypoglycemia was termed "minor".

\section{Statistical Analyses}

Data were validated and checked for consistency and error before analysis using the SAS analytical software package (Version 9.4, SAS Institute Inc., North Carolina, USA), as previously described [24]. ANOVA tests ( $F$ test when variance homogeneity, Welch test when variance heterogeneity) and Chi-squared tests were conducted for analyses between groups. In order to validate the MMAS- 8 modification, a Cronbach's $\alpha$ test was performed to assess the internal consistency and reliability of the MMAS- 8 scores, which results in an $\alpha$ value of 0.70 . This indicates the reliability is "acceptable", following the criterion that $\alpha \geq 0.70$ indicates "acceptable" internal consistency [27]. Logistic regression analysis was used to estimate the association of bolus insulin injection timing with responses to the MMAS-8 questionnaire and non-adherence, using the pre-meal cohort as reference group, yielding odds ratios (OR) and $95 \%$ confidence intervals (CI). The models were also stratified by $\mathrm{HbA}_{1 \mathrm{c}}$ levels and the number of bolus injections. Preliminary models were developed without the inclusion of control variables, as well as models adjusted for the following factors: sex, BMI, education, country, age, age when diagnosed, times per day injecting short-acting insulin, times per day injecting long-acting insulin, intake of oral glucose-lowering therapies and parental non-insulin glucose-lowering medication, an interaction between age and age when diagnosed, and an interaction between times per day injecting short-acting insulin and times per day injecting long-acting insulin. The interaction terms were included as these factors were deemed relevant 
and it was expected that their values would depend on one another. Mean results were reported \pm standard deviation (SD) and a $p$ value less than 0.05 was considered significant.

\section{RESULTS}

\section{Insulin Dose Timing}

A total of 3758 respondents with type 2 diabetes completed the survey; of these respondents 1509 were treated with bolus insulin and examined further. However, 26 respondents selected "other" dose timing and were excluded from further analysis. Of the remaining 1483 respondents, the majority (58\%) of respondents reported only administering their insulin prior to eating (pre-meal cohort). However, $24 \%$ of the respondents reported administering insulin during or after (post-meal cohort) and 18\% varied between before, during, or after eating (mixed cohort). Exclusion of the patients that varied their dosing between before, during, or after eating resulted in a sample comprising 1218 respondents.

\section{Respondent Demographics}

Respondent demographics varied depending on the timing of the bolus insulin (Table 1). Across timing of bolus insulin there was a statistically significant difference with respect to age, years since diagnosis, years on insulin, and BMI of respondents $(p<0.0001)$. The post-meal cohort were younger, had been diagnosed with type 2 diabetes more recently, had been taking insulin for a shorter length of time, and had a lower BMI, compared to the pre-meal cohort. The percentage of respondents that were educated to college or university level and employed or studying also differed significantly between the pre-meal and the post-meal cohorts $(p<0.0001)$. Respondents in the post-meal cohort were more likely to be educated to

Table 1 Respondent demographics assessed according to insulin dose timing

\begin{tabular}{|c|c|c|c|}
\hline & $\begin{array}{l}\text { Pre-meal cohort } \\
(N=864)\end{array}$ & $\begin{array}{l}\text { Post-meal cohort } \\
(N=354)\end{array}$ & $\begin{array}{l}\text { Total } \\
(N=1218)\end{array}$ \\
\hline Male (\%) & 60 & 64 & 61 \\
\hline Age $(\text { years })^{b}$ & $54 \pm 13$ & $45 \pm 14$ & $52 \pm 14$ \\
\hline Educated to college or university level $(\%)^{\mathrm{b}}$ & 39 & 61 & 46 \\
\hline School or paid/unpaid employment $(\%)^{\mathrm{b}}$ & 40 & 66 & 48 \\
\hline Unemployed, on sick leave, or retired (\%) & 60 & 34 & 52 \\
\hline BMI $\left(\mathrm{kg} / \mathrm{m}^{2}\right)^{\mathrm{b}}$ & $31 \pm 7$ & $29 \pm 9$ & $30 \pm 8$ \\
\hline Years since diagnosis ${ }^{\mathrm{b}}$ & $13 \pm 9$ & $8 \pm 7$ & $11 \pm 8$ \\
\hline Years on insulin ${ }^{\mathrm{b}}$ & $7 \pm 6$ & $6 \pm 5$ & $7 \pm 6$ \\
\hline \multicolumn{4}{|l|}{ Region (\%) } \\
\hline North America $(N=219)^{a}$ & 18 & 17 & 18 \\
\hline Europe $(N=653)^{\mathrm{a}}$ & 55 & 49 & 54 \\
\hline South America $(N=346)^{a}$ & 26 & 34 & 28 \\
\hline
\end{tabular}

$B M I$ body mass index

${ }^{a}$ A significant association with $p<0.05$ between variable and time of bolus injection (i.e., pre-meal or post-meal)

b A significant association with $p<0.0001$ between variable and time of bolus injection 
college or university level, and employed or studying, in comparison to the pre-meal cohort.

\section{Insulin Adherence}

After adjustment for potential confounding variables and exclusion of respondents due to missing or unrealistic confounding factor values, the post-meal was more likely to report non-adherence in the MMAS- 8 questionnaire than the pre-meal cohort [unadjusted model, $\mathrm{OR}=2.35,95 \%$ CI 1.83-3.03, $p<0.001$; adjusted model, OR $=1.50,95 \%$ CI $1.10-2.05$, $p<0.01]$ (Table 2). This was also true when stratifying by $\mathrm{HbA}_{1 \mathrm{c}}$ (Table 2 ), and by number of bolus injections, though the effect was not significant for patients taking more than three injections. Analysis of the individual items of the adherence questionnaire (Table 3 ) showed that the post-meal cohort significantly more often reported non-adherence in each of the components of the MMAS-8, compared to the pre-meal cohort $(p<0.001)$.

\section{Diabetes Education Program Participation}

Participation in one-on-one education programs varied significantly depending on the timing of insulin injection $(p<0.001)$. The post-meal cohort was more likely to have attended one-on-one education programs compared to the pre-meal (63\% versus 51\%). Attendance at group or class education programs was also significantly different across insulin dose timing $(p<0.05)$; a greater proportion of the post-meal cohort attended these programs than the pre-meal (43\% versus $41 \%$ ). Participation in online classes on diabetes and its treatment also differed significantly with insulin dose timing $(p<0.001)$; respondents in the post-meal cohort more often participated than the pre-meal ( $36 \%$ versus $25 \%)$.

Table 2 Association between time of bolus injection and non-adherence in all patients and stratified by $\mathrm{HbA}_{1 \mathrm{c}}$ and number of daily insulin injections

\begin{tabular}{|c|c|c|c|}
\hline & $\begin{array}{l}\text { Pre-meal } \\
\text { cohort }\end{array}$ & $\begin{array}{l}\text { Post-meal cohort - adjusted } \\
\text { model }^{\text {a }} \text {, OR }[95 \% \text { CI }]\end{array}$ & $\begin{array}{l}\text { Post-meal cohort - unadjusted } \\
\text { model, OR }[95 \% \mathrm{CI}]\end{array}$ \\
\hline All $(N=1218)$ & Reference & $1.50^{*}[1.10-2.05]$ & $2.35^{* * *}[1.83-3.03]$ \\
\hline $\mathrm{HbA}_{1 \mathrm{c}}<9 \%(N=701)$ & Reference & $1.54^{*}[1.00-2.35]$ & $2.32^{* * *}[1.65-3.26]$ \\
\hline $\mathrm{HbA}_{\mathrm{lc}} \geq 9 \%(N=390)$ & Reference & $2.86^{* * *}[1.50-5.46]$ & $3.07^{* * *}[1.99-4.73]$ \\
\hline $\begin{array}{l}\mathrm{HbA}_{1 \mathrm{c}}<9 \% \text { and }<3 \\
\quad \text { injections }(N=267)\end{array}$ & Reference & $2.37^{*}[1.17-4.80]$ & $3.09^{* * *}[1.86-5.14]$ \\
\hline $\begin{array}{l}\mathrm{HbA}_{1 \mathrm{c}} \geq 9 \% \text { and }<3 \\
\quad \text { injections }(N=195)\end{array}$ & Reference & $4.97^{*}[1.77-13.99]$ & $4.53^{* * *}[2.45-8.38]$ \\
\hline $\begin{array}{l}\mathrm{HbA}_{1 \mathrm{c}}<9 \% \text { and } \geq 3 \\
\quad \text { injections }(N=434)\end{array}$ & Reference & $1.20[0.63-2.26]$ & $1.58[0.97-2.57]$ \\
\hline $\begin{array}{l}\mathrm{HbA}_{1 \mathrm{c}} \geq 9 \% \text { and } \geq 3 \\
\text { injections }(N=195)\end{array}$ & Reference & $2.14[0.70-6.50]$ & $1.92 *[1.02-3.59]$ \\
\hline
\end{tabular}

$B M I$ body mass index, $C I$ confidence interval, $H b A_{l c}$ glycated hemoglobin, $O R$ odds ratio

a Adjusted for sex, BMI, education, country, age, age when diagnosed, an interaction between age and age when diagnosed, times per day injecting short-acting insulin, times per day injecting long-acting insulin, an interaction between times per day injecting short-acting insulin and times per day injecting long-acting insulin, intake of tablets and non-insulin diabetes medication using a needle

Significant difference to the pre-meal cohort indicated by ${ }^{*} p<0.05,{ }^{* *} p<0.001,{ }^{* * *} p<0.0001$ 
Table 3 MMAS-8 questionnaire results based on insulin dose timing

\begin{tabular}{lll}
\hline MMAS-8 components & $\begin{array}{l}\text { Pre-meal cohort } \\
(\boldsymbol{N}=\mathbf{8 6 4})\end{array}$ & $\begin{array}{l}\text { Post-meal cohort } \\
(\boldsymbol{N}=\mathbf{3 5 4})\end{array}$ \\
\hline Sometimes forget to take insulin & $32 \%$ & $53 \%^{* * *}$ \\
Had days not taking insulin in the past 2 weeks & $20 \%$ & $39 \%^{* * *}$ \\
Forget to bring insulin when leave home & $25 \%$ & $34 \%^{* *}$ \\
Did take all insulin the day before the questionnaire & $88 \%$ & $77 \%^{* * *}$ \\
Difficulty remembering to take all insulin (never) & $55 \%$ & $35 \%^{* * *}$ \\
Cut back or stop taking insulin & $17 \%$ & $32 \%^{* * *}$ \\
Stop taking insulin when symptoms controlled & $17 \%$ & $31 \%^{* * *}$ \\
Feel hassled about sticking to treatment plan & $44 \%$ & $55 \%^{* *}$ \\
\hline
\end{tabular}

MMAS-8 8-item Morisky Medication Adherence Scale

Significant difference to the pre-meal cohort indicated by ${ }^{*} p<0.05,{ }^{* *} p<0.001,{ }^{* * *} p<0.0001$

\section{Experience with Hypoglycemic Events}

Of respondents that experienced minor hypoglycemic events $(N=1003)$, there was a significant variation in the frequency of minor hypoglycemic events based on insulin dose timing $(p<0.0001)$. More respondents in the post-meal cohort reported experiencing minor hypoglycemic events at least once a week than the pre-meal (50\% versus 35\%). There was also a significant difference with respect to major hypoglycemic events across insulin dose timing $(p<0.0001)$, as more respondents in the post-meal cohort had experienced a major hypoglycemic event than the pre-meal (38\% versus $26 \%)$. In line with this increased frequency of hypoglycemia, more respondents in the post-meal cohort (63\%) agreed that "taking insulin increases the risk of low blood sugar" than the pre-meal cohort $(54 \%)(p=0.047)$.

\section{Glycemic Control}

Of respondents that knew their most recent $\mathrm{HbA}_{1 \mathrm{c}}$ and were not excluded because of $\mathrm{HbA}_{1 \mathrm{c}}$ $>15 \%(140.4 \mathrm{mmol} / \mathrm{mol})(N=884)$, the median $\mathrm{HbA}_{1 \mathrm{c}}$ was similar across the three cohorts: $8.0 \% \quad(64.0 \mathrm{mmol} / \mathrm{mol} \pm 2.39)$, and $7.6 \%$ $(60.0 \mathrm{mmol} / \mathrm{mol} \pm 2.36)$ for the post-meal and pre-meal cohorts, respectively $(p=0.22)$.
Despite this, $\mathrm{HbA}_{1 \mathrm{c}}$ category was significantly different across insulin dose timing $(p<0.0006)$, with a greater proportion of respondents in the post-meal cohort having $\mathrm{HbA}_{1 \mathrm{c}} \geq 9 \%(74.9 \mathrm{mmol} / \mathrm{mol})$ compared to the pre-meal (40\% versus 29\%) (Fig. 1).

The frequency of testing blood glucose was significantly different across timing of insulin injections $(p<0.0001)$, as the post-meal cohort less often reported that they always tested their blood glucose before injecting insulin compared to the pre-meal cohort (36\% versus 54\%) (Fig. 2). Additionally, there were significant differences with respect to the daily frequency of bolus insulin injections across insulin dose timing $(p<0.0001)$, as a greater proportion of the post-meal reported injecting less than three times a day than the pre-meal cohort $(56 \%$ versus $36 \%$ ).

\section{Respondent Preference}

The majority of respondents in both the pre-meal and post-meal cohorts would prefer a type of bolus insulin that they could take before, after, or during meals as deemed necessary. However, preference for this differed significantly across cohorts $(p<0.0001)$ with greater frequency of preference in the post-meal cohort (87\%) compared to the pre-meal cohort (74\%). 


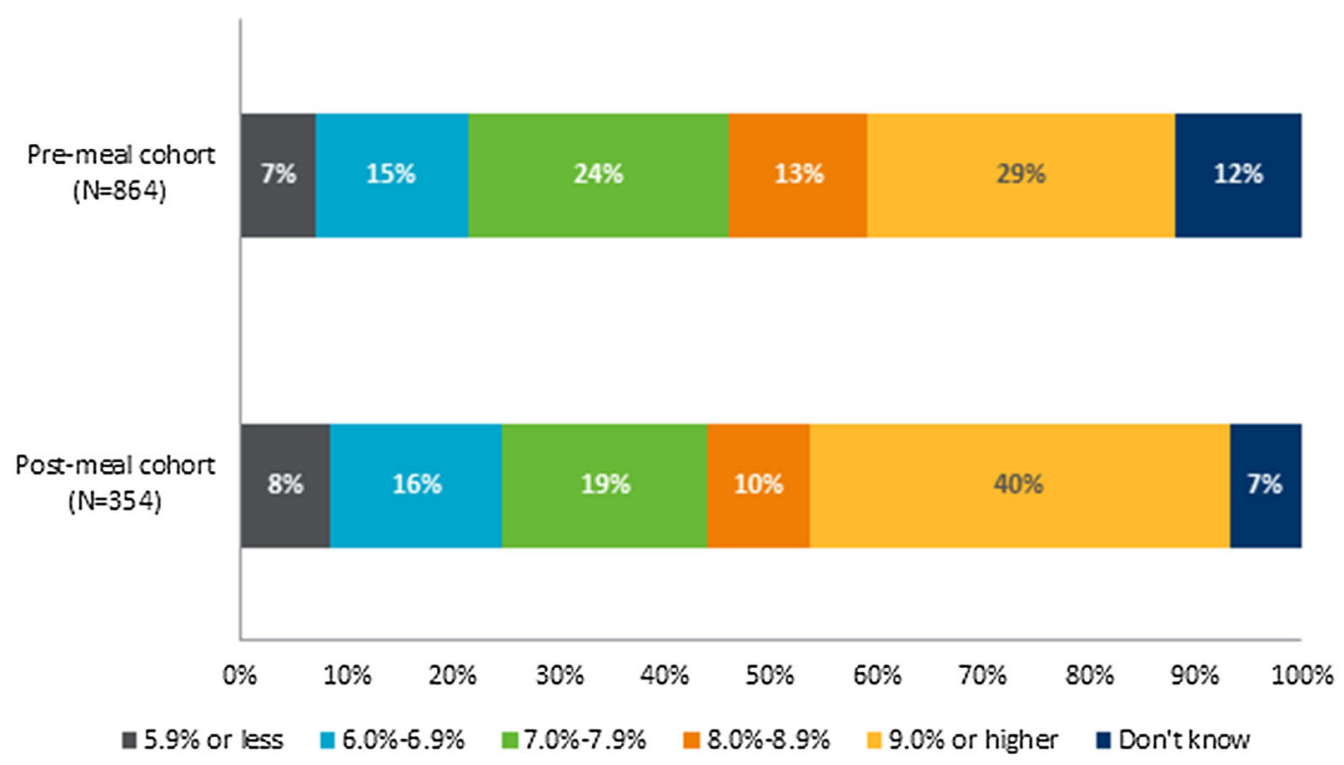

Fig. $1 \mathrm{HbA}_{1 \mathrm{c}}$ in respondents with different timings of insulin dosing $(N=1218)$. Results based on responses to the following question: "In what range is your most recent

measured level of long-term blood sugar $\left(\mathrm{HbA}_{1 \mathrm{c}}\right)$ ?” The proportion of respondents in each $\mathrm{HbA}_{1 \mathrm{c}}$ category varied significantly depending on respondent cohort $(p<0.0006)$

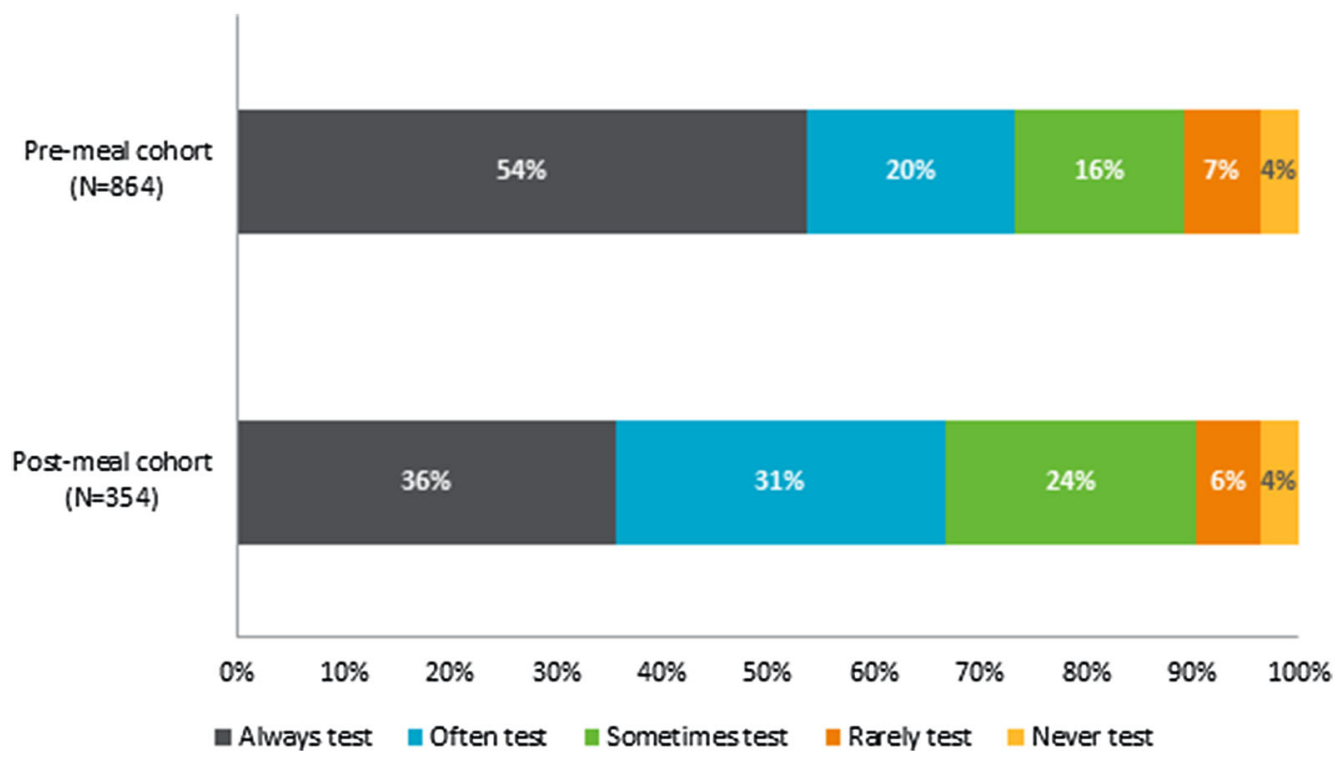

Fig. 2 Frequency of blood glucose testing prior to administration in respondents with different timings of insulin dosing $(N=1218)$. Results based on responses to the following question: "Please indicate how often you do the described action related to injecting insulin: I test my blood sugar before injecting the insulin?" The frequency of testing varied significantly depending on respondent cohort $(p<0.001)$ 


\section{DISCUSSION}

The present analysis provides insight into the relationship between insulin dose timing, insulin treatment adherence, and glycemic control. The findings suggest that respondents who do not comply with general guidance on insulin dose timing are more likely to exhibit other non-adherent behaviors and have poorer glycemic control.

A high proportion of respondents reported never adhering to guidelines on insulin dose timing (24\%, post-meal cohort). Moreover, poor glycemic control was prevalent in this cohort, putting them at increased risk of developing diabetic complications [2]. Similarly, a recent study in people with type 1 diabetes identified higher $\mathrm{HbA}_{1 \mathrm{c}}$ in people dosing insulin after, compared to before, meals [28]. The present analysis identified respondents who injected insulin post-meal were younger, had shorter duration of diabetes, had the highest level of college or university education, were more likely to be employed, and more frequently participated in diabetes education programs. These data suggest that factors other than lack of diabetes education, education, or low socioeconomic status should be considered in explaining this non-adherent behavior.

Experience with prior hypoglycemic events has been reported to significantly impact adherence to insulin treatment $[14,15]$. The post-meal cohort reported more frequent hypoglycemic events and were more likely to agree that insulin increases the risk of hypoglycemic events, compared to the pre-meal cohort. It has been reported that inappropriate insulin dose timing is associated with increases in hypoglycemic events, and worrying about the recurrence of these events [29]. As worrying about recurrent hypoglycemia is associated with reduced insulin adherence [30], inappropriate insulin timing may decrease adherence indirectly. Alleviating the risk of hypoglycemia by facilitating appropriate timing of insulin injections could improve adherence to treatment.

Respondents in the post-meal cohort were more likely to be educated to college or university level, and employed or studying. This may be due to the analysis confounding by age or diabetes duration, as respondents in the post-meal cohort were younger and had fewer years since diagnosis. However, another study of people with type 1 and type 2 diabetes found a similar relationship between employment and dose timing, which could not be fully explained by age [29]. Higher levels of employment may reflect that respondents in the post-meal cohort are more likely to lead busier lives that impede adherence to insulin treatment and dose timing [15]. Previous studies that have identified a significant negative effect of patient lifestyle on adherence to insulin [15]. Diabetes treatments that are more compatible with people's lifestyles may assist people in adhering to insulin treatment.

The post-meal cohort reported higher levels of participation in all types of education programs, non-adherent behavior, and $\mathrm{HbA}_{1 \mathrm{c}}$ $(\geq 9 \%, 74.9 \mathrm{mmol} / \mathrm{mol})$. Whilst this group may have had more frequent referrals to education programs because of non-adherence and high $\mathrm{HbA}_{1 \mathrm{c}}$, these results may indicate that participation in these programs does not improve patient adherence. Other studies have identified that education programs have an inconsistent relationship with patient adherence [22, 23], and perhaps such programs could be improved by placing greater emphasis on the importance of dosing insulin pre-meal [28, 29].

Selection of an appropriate medication formulation that considers patient preference and lifestyle is also important [21]. This analysis found that respondents preferred a form of bolus insulin they can administer, before, after, or during meals as they see fit. The post-meal cohort was more likely to prefer this formulation of insulin than the other cohorts. This is in line with their increased probability of forgetting insulin and the hypothesis that flexible dosing may be easier to fit around their employment. Such a formulation of insulin could be a particularly pertinent treatment strategy for people that dose bolus insulin post-meal, and may improve adherence and outcomes.

There were a number of limitations to this analysis. The cross-sectional design means causal relationships could not be identified as a result of confounding factors and the risk of reverse causation. Moreover, data was self-reported; thus, 
lack of clinician validation to eliminate potential bias associated with respondent recall limits data validity [31]. Selection bias may have been introduced, as the survey required respondents to have computer access, an email address, and sufficient computer literacy to participate. Additionally, respondent participation was optional and factors such as respondent demographics may influence participation. However, the demographics data of this analysis were similar to the global large-scale Hypoglycemia Assessment Tool study, which found that the mean age of people with type 2 diabetes was 60.8 years and average diabetes duration was 13.7 years [32]. This suggests the respondent population may be representative of the broader population of people with type 2 diabetes. Furthermore, the survey did not distinguish between the different types of bolus insulin available. The present analysis followed general guidance that insulin should be administered within 30 min before a meal, although rapid acting insulin formulations also exist that can be dosed post-meal $[4,5]$. Another limitation was potential variation in the pre-meal cohort, as the analysis could not differentiate between respondents who dosed immediately before meals and those who dosed longer before meals. Finally, adapting the MMAS- 8 by adding the term "insulin" had not previously been validated. However, a Cronbach's $\alpha$ test found that the adapted MMAS- 8 used in this study was acceptably reliable and previous studies have similarly adapted the MMAS-8 in hypertension and inflammatory bowel disease [33, 34].

\section{CONCLUSION}

Approximately 24\% of respondents reported consistently failing to comply with general guidelines for bolus insulin dose timing, with higher risk of non-adherence, experience of hypoglycemia, and poor glycemic control $\left(\mathrm{HbA}_{1 \mathrm{c}} \geq 9 \%, 74.9 \mathrm{mmol} / \mathrm{mol}\right)$. These respondents more often attended diabetes education programs and further research is necessary to confirm whether such programs are sufficient to manage all adherence issues. Respondent preference for bolus insulin with flexible dosing raises the hypothesis that such a formulation would effectively provide people with the flexibility to maintain adherence despite a busy lifestyle.

\section{ACKNOWLEDGEMENTS}

Incentive, an economic consultancy firm, received funding from Novo Nordisk to conduct this study. Editorial support for the manuscript was provided by Adelphi Values and funded by Novo Nordisk. Article processing charges were also funded by Novo Nordisk. All authors had full access to all of the data in this study and take complete responsibility for the integrity of the data and accuracy of the data analysis. All named authors meet the International Committee of Medical Journal Editors (ICMJE) criteria for authorship for this manuscript, take responsibility for the integrity of the work as a whole, and have given final approval for the version to be published.

Disclosures. Mette Bøgelund is an employee of Incentive, and has received consultancy fees from Novo Nordisk A/S. Nicolaas Schaper declares that he has no relevant conflict of interest to disclose. Annie Nikolajsenis an employee of Novo Nordisk A/S. Anna Sandbergis an employee of Novo Nordisk A/S. Sarah Buchs was an employee of Novo Nordisk A/S at the time of the study.

Compliance with Ethics Guidelines. All procedures followed were in accordance with the ethical standards of the responsible committee on human experimentation (Institutional Review Board Services, Canada) and with the Helsinki Declaration of 1964, as revised in 2013. Informed consent was obtained from all patients for being included in the study.

Data Availability. The datasets generated during and/or analyzed during the current study are not publicly available because of ongoing analysis for further publications, but they are available from the corresponding author on reasonable request. 
Previous Presentation. Initial results from this manuscript were presented at the ISPOR 2016 19th Annual European Congress; Vienna, Austria.

Open Access. This article is distributed under the terms of the Creative Commons Attribution-NonCommercial 4.0 International License (http://creativecommons.org/licenses/ by-nc/4.0/), which permits any noncommercial use, distribution, and reproduction in any medium, provided you give appropriate credit to the original author(s) and the source, provide a link to the Creative Commons license, and indicate if changes were made.

\section{REFERENCES}

1. Holman RR, Thorne KI, Farmer AJ, et al. Addition of biphasic, prandial, or basal insulin to oral therapy in type 2 diabetes. $\mathrm{N}$ Engl $\mathrm{J}$ Med. 2007;357(17):1716-30.

2. Stratton IM, Adler AI, Neil HA, et al. Association of glycaemia with macrovascular and microvascular complications of type 2 diabetes (UKPDS 35): prospective observational study. BMJ. 2000;321(7258):405-12.

3. Pantalone KM, Hobbs TM, Wells BJ, et al. Clinical characteristics, complications, comorbidities and treatment patterns among patients with type 2 diabetes mellitus in a large integrated health system. BMJ Open Diabetes Res Care. 2015;3(1):e000093.

4. American Diabetes Association. Insulin administration. Diabetes Care. 2004;27(suppl 1):s106-7.

5. National Institute for Health and Care Excellence. Insulin therapy in type 2 diabetes 2016 . https://cks. nice.org.uk/insulin-therapy-in-type-2-diabetes\#! scenario. Accessed 16 Oct 2017.

6. Food and Drug Administration. Humalog label 2011. https://www.accessdata.fda.gov/drugsatfda docs/label/2013/020563s115lbl.pdf. Accessed 16 Oct 2017.

7. Food and Drug Administration. Novolog label 2015. https://www.accessdata.fda.gov/drugsatfda docs/label/2012/020986s057lbl.pdf. Accessed 16 Oct 2017.
8. Food and Drug Administration. Apidra label 2015. https://www.accessdata.fda.gov/drugsatfda_docs/ label/2008/021629s015lbl.pdf. Accessed 16 Oct 2017.

9. European Medicines Agency. Humalog-summary of product characteristics 2016. http://www.ema. europa.eu/docs/en_GB/document_library/EPAR_Product_Information/human/000088/WC5000503 32.pdf. Accessed 16 Oct 2017.

10. European Medicines Agency. NovoRapid-summary of product characteristics 2016. http://www. ema.europa.eu/docs/en_GB/document_library/EPAR _-_Product_Information/human/000258/WC500030 372.pdf. Accessed 16 Oct 2017.

11. European Medicines Agency. Apidra-summary of product characteristics 2016. http://www.ema. europa.eu/docs/en_GB/document_library/EPAR_-Product_Information/human/000557/WC5000252 50.pdf. Accessed 16 Oct 2017.

12. Brod M, Rana A, Barnett AH. Adherence patterns in patients with type 2 diabetes on basal insulin analogues: missed, mistimed and reduced doses. Curr Med Res Opin. 2012;28(12):1933-46.

13. Peyrot M, Rubin RR, Kruger DF, Travis LB. Correlates of insulin injection omission. Diabetes Care. 2010;33(2):240-5.

14. Farsaei S, Radfar M, Heydari Z, Abbasi F, Qorbani M. Insulin adherence in patients with diabetes: risk factors for injection omission. Prim Care Diabetes. 2014;8(4):338-45.

15. Davies MJ, Gagliardino JJ, Gray LJ, et al. Real-world factors affecting adherence to insulin therapy in patients with type 1 or type 2 diabetes mellitus: a systematic review. Diabet Med. 2013;30(5):512-24.

16. Cryer PE, Davis SN, Shamoon H. Hypoglycemia in diabetes. Diabetes Care. 2003;26(6):1902-12.

17. Schectman JM, Nadkarni MM, Voss JD. The association between diabetes metabolic control and drug adherence in an indigent population. Diabetes Care. 2002;25(6):1015-21.

18. DiBonaventura M, Wintfeld N, Huang J, Goren A. The association between nonadherence and glycated hemoglobin among type 2 diabetes patients using basal insulin analogs. Patient Prefer Adherence. 2014;8:873-82.

19. Donnelly LA, Morris AD, Evans JM. Adherence to insulin and its association with glycaemic control in patients with type 2 diabetes. QJM. 2007;100(6):345-50. 
20. American Diabetes Association. Standards of medical care in diabetes-2013. Diabetes Care. 2013;36(Suppl 1):S11-66.

21. Nau DP. Recommendations for improving adherence to type 2 diabetes mellitus therapy-focus on optimizing oral and non-insulin therapies. Am J Manag Care. 2012;18(3 Suppl):S49-54.

22. García-Pérez L-E, Álvarez M, Dilla T, Gil-Guillén V, Orozco-Beltrán D. Adherence to therapies in patients with type 2 diabetes. Diabetes Ther. 2013;4(2):175-94.

23. Haynes RB, Ackloo E, Sahota N, McDonald HP, Yao $\mathrm{X}$. Interventions for enhancing medication adherence. Cochrane Database Syst Rev. 2008;2:Cd000011.

24. Feher MD, Brazier J, Schaper N, Vega-Hernandez G, Nikolajsen A. Patients' with type 2 diabetes willingness to pay for insulin therapy and clinical outcomes. BMJ Open Diabetes Res Care. 2016;4(1):e000192.

25. Morisky DE, Green LW, Levine DM. Concurrent and predictive validity of a self-reported measure of medication adherence. Med Care. 1986;24(1):67-74.

26. Morisky DE, Ang A, Krousel-Wood M, Ward HJ. Predictive validity of a medication adherence measure in an outpatient setting. J Clin Hypertens (Greenwich). 2008;10(5):348-54.

27. DeVon HA, Block ME, Moyle-Wright P, et al. A psychometric toolbox for testing validity and reliability. J Nurs Scholarsh. 2007;39(2):155-64.

28. Peters A, Van Name MA, Thorsted BL, Piltoft JS, Tamborlane WV. Postprandial dosing of bolus insulin in patients with type 1 diabetes: a cross-sectional study using data from the T1D exchange registry. Endocr Pract. 2017. doi:10.4158/ EP171813.OR.

29. Tamborlane WV, Pfeiffer KM, Brod M, et al. Understanding bolus insulin dose timing: the characteristics and experiences of people with diabetes who take bolus insulin. Curr Med Res Opin. 2017;33(4):639-45.

30. Lopez JM, Annunziata K, Bailey RA, Rupnow MF, Morisky DE. Impact of hypoglycemia on patients with type 2 diabetes mellitus and their quality of life, work productivity, and medication adherence. Patient Prefer Adherence. 2014;8:683-92.

31. Willaing I, Rogvi SA, Bogelund M, Almdal T, Schiotz M. Recall of HbA1c and self-management behaviours, patient activation, perception of care and diabetes distress in Type 2 diabetes. Diabet Med. 2013;30(4):e139-42.

32. Khunti K, Alsifri S, Aronson R, et al. Rates and predictors of hypoglycaemia in 27,585 people from 24 countries with insulin-treated type 1 and type 2 diabetes: the global HAT study. Diabetes Obes Metab. 2016;18(9):907-15.

33. Oliveira-Filho AD, Barreto-Filho JA, Neves SJ, Lyra Junior DP. Association between the 8-item Morisky Medication Adherence Scale (MMAS-8) and blood pressure control. Arq Bras Cardiol. 2012;99(1):649-58.

34. Trindade AJ, Ehrlich A, Kornbluth A, Ullman TA. Are your patients taking their medicine? Validation of a new adherence scale in patients with inflammatory bowel disease and comparison with physician perception of adherence. Inflamm Bowel Dis. 2011;17(2):599-604. 